\title{
Interactions between Propagating Flame Fronts and Obstacles in an Explosion Chamber with a H/L Ratio of 0.86
}

\author{
${ }^{\dagger}$ Dal Jae Park \\ Dept. of Safety Engineering, Seoul National University of Science and Technology, Seoul \\ 139-743, Korea \\ (Received January 4, 2013; Revised February 4, 2013; Accepted February 4, 2013)
}

요 약

높이/길이 비가 0.86 을 가지는 폭발챔버 내에서 전파하는 화염과 서로 다른 형태의 다중 장애물 사이의 상호작 용을 조사하기 위해 폭발실험을 수행하였다. 챔버 내에 장애물 형태는 삼각기둥, 사각기둥 및 원통형으로 변화시 켰으며, 장애물의 blockage ratio는 0.43 으로 하였다. 전파하는 화염과 장애물 형태에 따른 상호작용을 조사하기 위 해 고속카메라를 사용하였으며, 고속카메라로 얻어진 화염 이미지로부터 장애물 주위의 국부 화염속도 및 그 화 염속도의 확률밀도함수를 계산하였다. 실험결과, 장애물 형태가 삼각형이었을 때 국부 화염속도가 가장 높게, 원 형에서는 가장 낮게 나타났으며, 장애물 후류에서의 국부 화염속도는 장애물 형태에 큰 의존성을 가지는 것으로 나타났다. 또한, 전파하는 화염이 장애물 후류의 미연소가스의 유동과 상호작용할 때 국부 화염속도의 확률밀도 함수는 화염속도가 높은 방향으로 광범위하게 분포되는 것으로 나타났다.

\begin{abstract}
Experimental studies were carried out to investigate the interactions between the propagating flame fronts and different multiple obstacles within an explosion chamber. The explosion chamber is $600 \mathrm{~mm}$ in height, $700 \times 700 \mathrm{~mm}^{2}$ in cross-section and has a $\mathrm{H} / \mathrm{L}$ value of 0.86 . Three different multiple obstacles with the blockage ratio of 0.43 were replaced within the chamber. The results showed that relatively higher local flame displacement speed was observed with the triangular obstacle while the lower was observed with the circular one. It was found that the local flame displacement speeds behind the obstacle were largely dependent on the obstacle types. It was also found that as the flame interacted with the flow field generated behind the obstacle, the probability density functions(PDFs) of the local flame displacement speed were extensively distributed toward higher speeds.
\end{abstract}

Key words : obstacles, local flame speed, height to length ratio, probability density functions

\section{Introduction}

Since the last thirty years, studies [1-9] on the effect of obstacles influencing the explosion strength are continuous outstanding research issues which need to be resolved in order to improve computational fluid dynamics tool capabilities. Although the results of the experiments [6-9] revealed that the interaction between propagating flames and obstacles is a key phenomenon in determining the strength of explosions, the more detailed data of local flame speeds between the propagating flame front and obstacles in a partially opened enclosure with a small height to length $(\mathrm{H} / \mathrm{L})$ ratio have not been clearly examined.

The main objectives of this work are to investigate the underlying mechanisms of local flame/obstacle interaction in premixed methane-air mixtures in a partially opened chamber with a small $\mathrm{H} / \mathrm{L}$ ratio of 0.86 and to provide experimental data necessary for the further validation of physical sub-models of CFD.

${ }^{\dagger}$ Corresponding author:pdj70@seoultech.ac.kr

Copyright (c) 2013 by The Korean Institute of Gas 


\section{Experimental methods}

The premixed methane-air mixtures with about 10 $\%$, equipments and experimental methods employed in this study are the same with the measurements explained in previous study[10-12]. Fig. 1 shows a schematic of the explosion chamber used in the work. The dimensions of explosion chamber are $600 \mathrm{~mm}$ in height, with a $700 \times 700 \mathrm{~mm}^{2}$ cross-section and a rectangular top-venting area of $700 \times 210 \mathrm{~mm}^{2}$. The flammable mixture within the chamber was ignited by about $10 \mathrm{kV}$ electric spark positioned at the center of the bottom wall. The configurations of the obstacles used in this work are indicated in Table 1. Three different multiple obstacles: cylindrical, square and triangular bars with a obstruction ratio of 0.43 were centered at $300 \mathrm{~mm}$ from the bottom of the

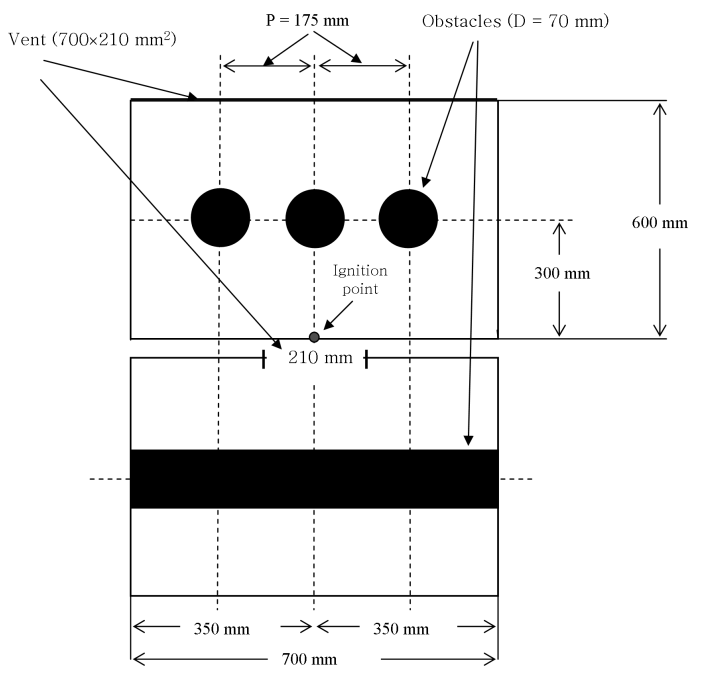

Fig. 1. Schematic of an explosion chamber.

Table 1. Configurations of all obstacles used

\begin{tabular}{|l|c|l|c|}
\hline \multicolumn{1}{|c|}{ Obstacles } & Symbol & \multicolumn{1}{|c|}{$\begin{array}{c}\text { Dimensions } \\
(\mathrm{mm})\end{array}$} & B.R \\
\hline Square Bars & MS & L700 $\times$ S70, P=175 & 0.43 \\
\hline Triangular Bars & MT & L700 $\times$ E.S.70, P=175 & 0.43 \\
\hline Circular Bars & MC & L700 $\times$ D 70, P=175 & 0.43 \\
\hline
\end{tabular}

B.R.: blockage ratio, L: length, D: diameter, S: side, E.S.: equal sides, P: pitch chamber. The data processing methods to examine the local flame-front characteristics between the propagating flames and the obstacles were the same with those described in the previous work [10].

\section{Results and discussion}

\subsection{Flame development}

Fig. 2 shows an example of a sequence of highspeed images of global flame structures taken with different multiple obstacles in the chamber. The time shown presents the elapsed time after ignition and subsequent flame images are at $20 \mathrm{~ms}$ intervals. Fig. 3 represents the temporal evolution of locally propagating flame front contours around different crosssection obstacles: square, triangle and circle within the chamber. In the Fig. 3 subsequent flame fronts for

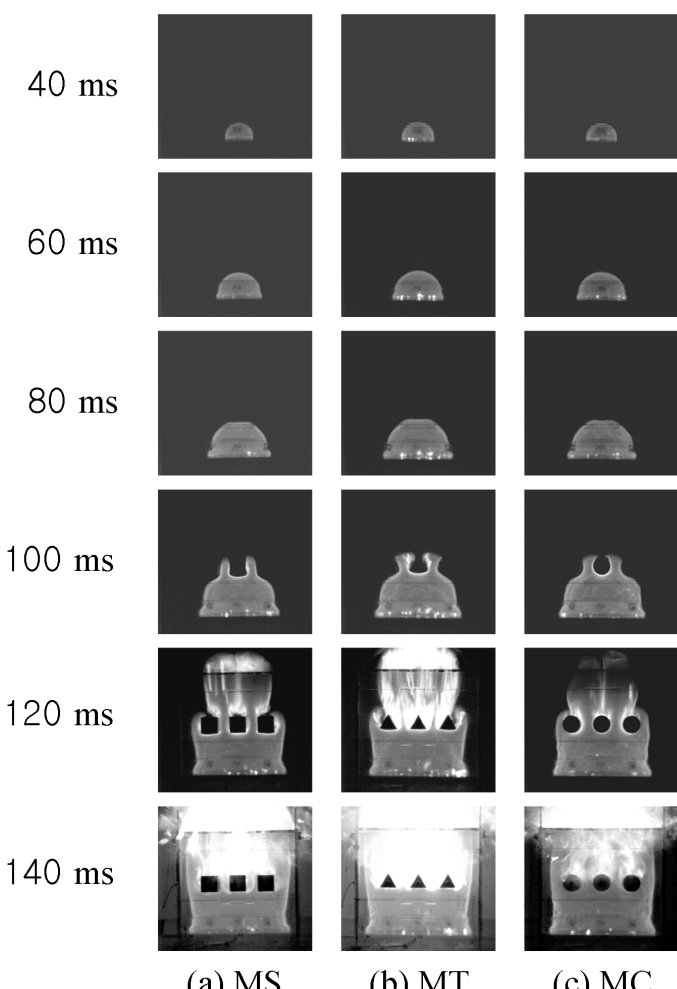

Fig. 2. A sequence of selected high speed images of global flame propagation for different multiple obstacles within the chamber (a) MS, (b) MT and (c) MC. 
the different obstacles are traced between 80 and 108 $\mathrm{ms}$ : the first contour is at $\mathrm{t}=80 \mathrm{~ms}$, and the last one at $108 \mathrm{~ms}$, with a separation of $2 \mathrm{~ms}$.

As shown in the Fig. 2, the flame is initiated with a hemispherical shape towards the chamber centerline until about $\mathrm{t}=80 \mathrm{~ms}$ after ignition. The flame consumes unburnt mixtures closer to the obstacle. And then, the flame approaches slowly the face of the obstacle due to the existence of a stagnation point. As the leading flame goes closer to the face of the ob-

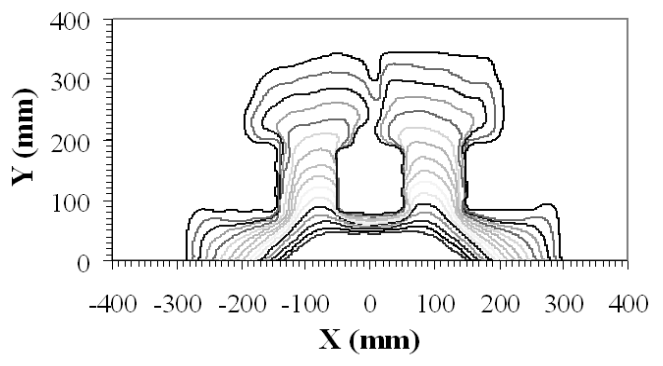

(a)

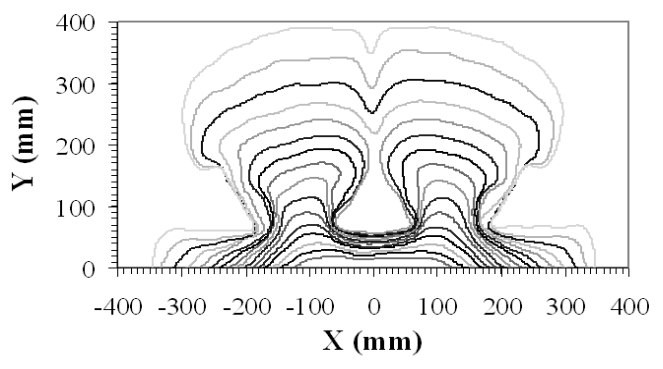

(b)

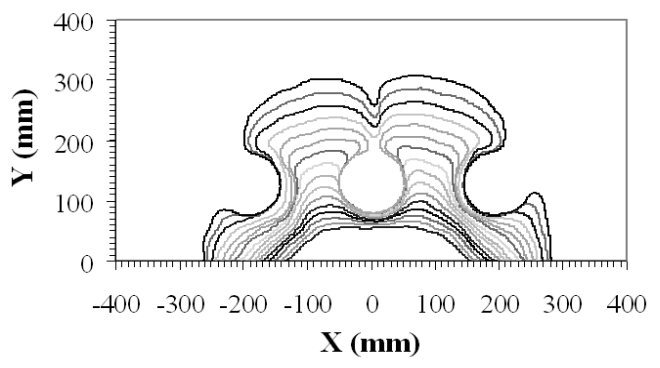

(c)

Fig. 3. Temporal evolution of flame contours (time interval $=2 \mathrm{~ms}$ ) for different obstacles in the chamber from 80 to $110 \mathrm{~ms}$ : (a) MS, (b) MT and (c) MC. stacle, it is clearly seen that the surface of the flame front becomes concave. The reason is that the existence of the obstacle in the path of the flame pushes unburnt mixture to the central region of the leading flame front. This phenomenon happens at about 84 $\mathrm{ms}$, regardless of the obstacle shapes.

During the flame interaction with the central obstacle, the two leading flame fronts starts to propagate towards the space between the central obstacle and side obstacles. As time goes on, the two leading flame fronts reconnect in the wake of the central obstacle with an expanded surface area. The flame reconnection occurred at about $108 \mathrm{~ms}$, regardless of the obstacle types. After the flame reconnection, the flame propagates towards the chamber exit. The travel time of the propagating flame front to the chamber exit occurred at about $112 \mathrm{~ms}$ (MT), $114 \mathrm{~ms}$ (MS) and $118 \mathrm{~ms}$ (MC). The delay time of the flame exiting the chamber was shorter with the triangular obstacle while the longest times occurred with the cylinder. After the flame front reached the chamber exit, the configuration of the flame front around the side obstacles with the vent become more complicated with the interaction of flow vortices.

\subsection{Statistics of local flame speed}

Here, local flame displacement speed, $S_{f d}$, was calculated along the flame front by dividing the distance along the normal line at each point by the time between two consecutive flame images from the flame contours displayed in the Fig. 3 [12]. The methods to estimate local flame displacement speed were the same with those described in the previous paper [10]. A statistical method of the probability density functions (PDFs) of local flame displacement speed obtained through the interactions between the propagating flame fronts and the obstacles were the same as described in the previous work [10]. The PDFs of local flame displacement speed for the different obstacles are displayed in Fig. 4.

Stage I occurs when propagating flames impinges on the front face of the central obstacle, facing the ignition point. As the leading flame fronts approaches the front face of the obstacle, the unburnt gas ahead of the front face of the obstacle deform the front of the flame surface propagating towards the obstacle, and this results in the flame deceleration in the laminar 


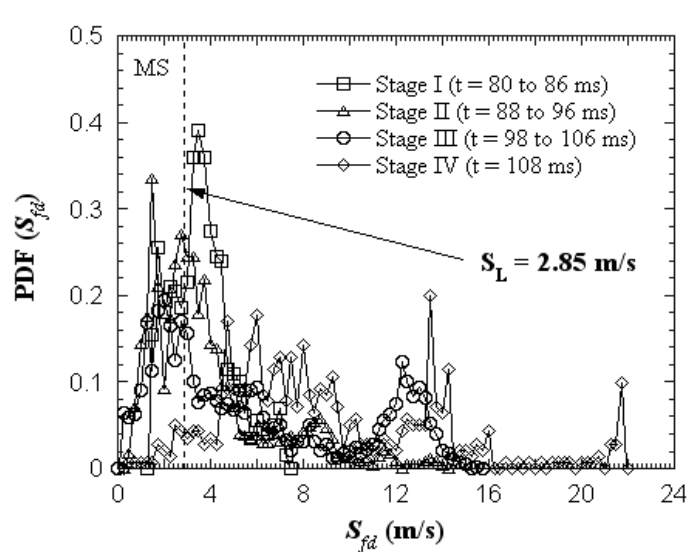

(a)

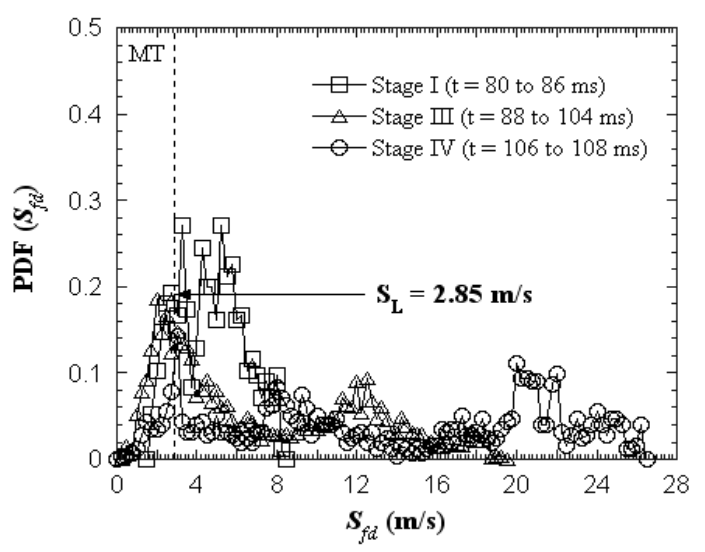

(b)

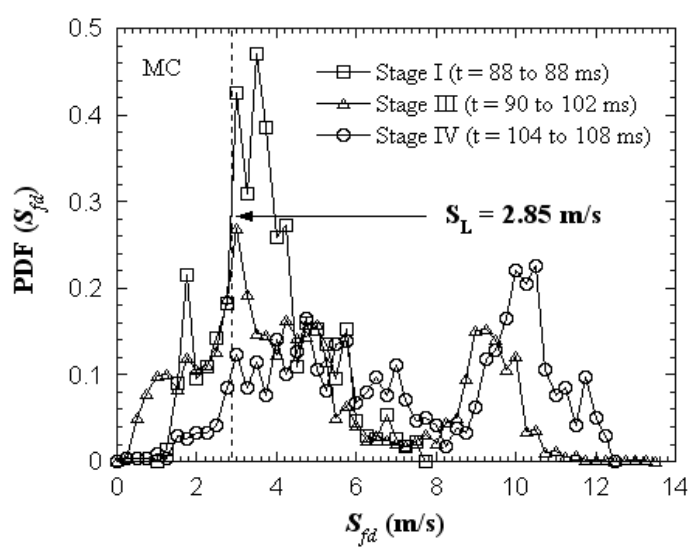

(c)

Fig. 4. PDFs of local flame displacement speed for different obstacles: (a) MS, (b) MT and (c) MC. flame and there is little opportunity for turbulence generation. The PDFs in this stage I is therefore skewed to lower displacement speeds than the laminar flame speed.

Stage II only occurs as the flame propagates around the lateral sides of the square obstacle. During this stage, small vortices are generated within the shear layer along the sides of the square. The PDFs during stage II had a positive skewness above the laminar flame speed, being more distributed to higher speeds than in stage I. This is associated with the weak flame acceleration generated caused by turbulence normal to the flame.

Stage III occurs as the flame interacts with obstacles from behind the central obstacle to flame reconnection. As the flame propagates behind the obstacle, disturbances of the flow in the wake of the obstacle causes turbulence near the flame front. This accelerates the flame normal to the direction of flow. However, the central region of lateral flame fronts propagating towards the side obstacles begins to become a concaved nature, this decelerates the flame parallel to the direction of flow. As results, the distribution of the PDFs widens towards higher and lower values during stage III. The PDFs were mostly skewed towards higher values indicating that the prevailing influence is increase of turbulence normal to the direction flow accelerating the flame. Stage IV occurs the flame interaction with obstacles after the flame reconnection. The PDFs have a similar trend to those of stage III. noticeably longer tail towards higher values than that of stage III. This tail is linked to flame acceleration generated caused by strong turbulence normal to the flame.

The mean, standard deviation, skewness and kurtosis of the flame displacement speed PDFs were calculated and are shown in Fig. 5 plotted against the different stages explained above. The mean displacement speed for the different obstacles was becoming higher through the stages and a maximum at stage IV. The standard deviation for the different obstacles was similar at all stages, excepting for stage IV. The MT caused the higher standard deviation for stage IV while the lower one was at the MC. Among the different obstacles, the MS had relatively higher skewness and kurtosis for stage IV while the MT and MC were almost similar at all stages. 

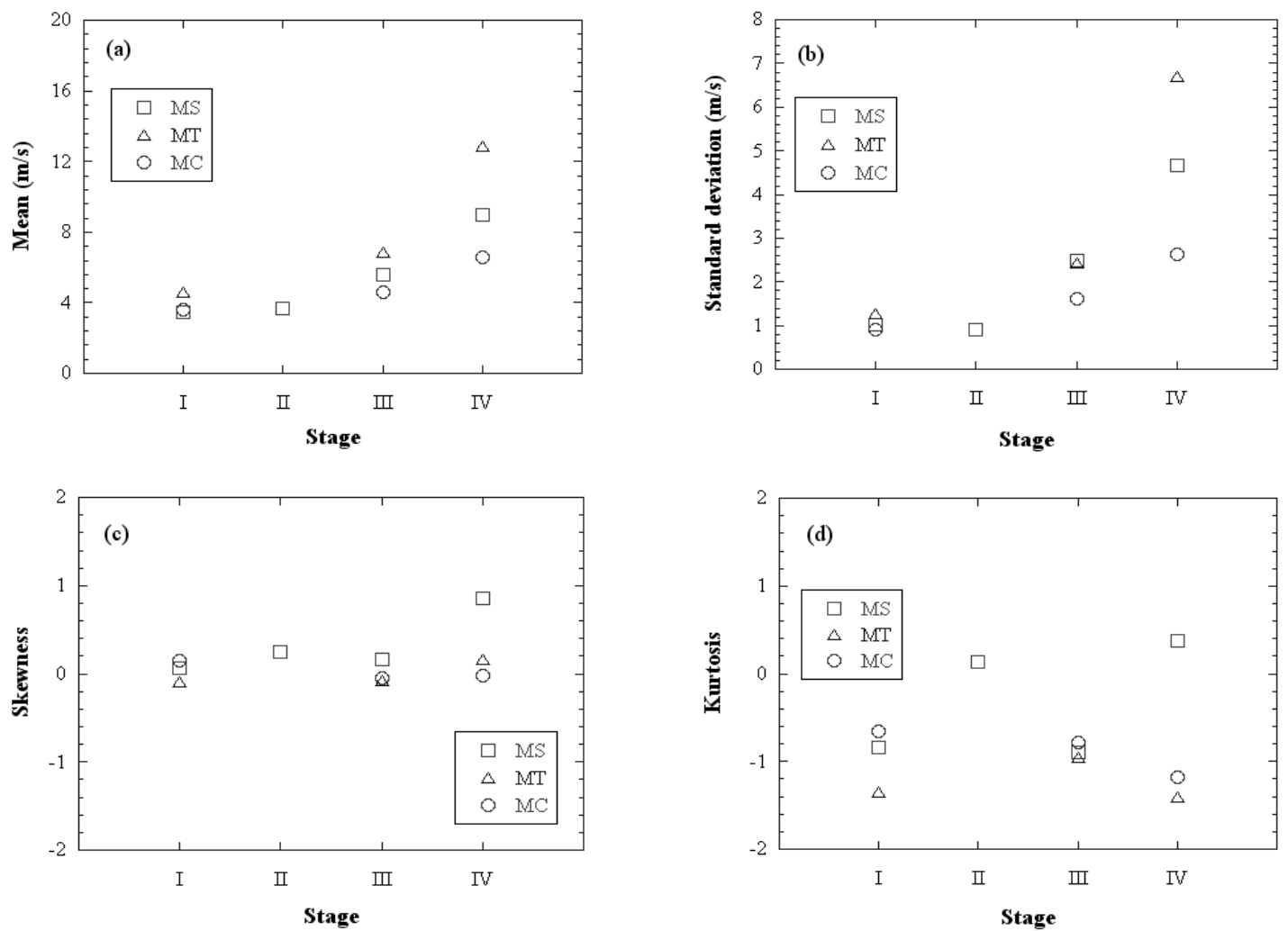

Fig. 5. Moments of the local flame displacement speed PDFs for different stages in Fig. 4; (a) mean (b) standard deviation (c) skewness and (d) kurtosis.

\section{Conclusions}

Experimental investigations were carried out to examine the interactions between propagating flames and three different multiple obstacles within a chamber with a $\mathrm{H} / \mathrm{L}$ ratio of 0.86 . The main findings gained from the present study are summarized as follows:

As the flame approaches the lower face of central obstacles, the central surface of the flame front become concave, this caused the slower local flame displacement speed. As the leading flame propagates behind the obstacle through the space between the right and lefts obstacles, this resulted in the acceleration of local flame speed. Simultaneously, as the laterally propagating flame interacts with the faces of side obstacles, it decelerates due to the generation of concave of the central surface of the later flame. Among the different obstacles, relatively higher local flame displacement speed was observed with the triangular obstacle while the lower was observed with the circular one. The flame displacement speeds behind the obstacle were largely sensitive to the obstacle configurations.

The local flame displacement speed PDFs during the stage IV, representing the flame interaction with the modified flow formed behind the obstacle were extensively distributed towards higher displacement speed.

\section{Acknowledgements}

The author gratefully acknowledges financial supports from Seoul National University of Science and Technology, Korea. 


\section{References}

[1] Moen, I.O., Donato, M., Knystautas, R. and Lee, J.H.S., "Flame acceleration due to turbulence produced by obstacles", Combustion and Flame, 39, 21-32 (1980)

[2] Moen, I.O. and Lee, J.H.S., "Pressure development due to turbulent flame propagation in large-scale methane-air explosions", Combustion and Flame, 47, 31-52 (1982)

[3] Hjertager, B.H., Fuhre, K., and Bjorkhaug, M., "Concentration effects on flame acceleration by obstacles in large-scale methane-air and propane-air vented explosions", Combustion Science and Technology, 62, 239-256 (1988)

[4] Phylaktou, H., \& Andrews, G.E., "Gas explosions in long closed vessels", Combustion Science and Technology, 77, 27-39 (1991)

[5] Fairweather, M., Hargrave, G.K, Ibrahim, S.S and Walker, D.G., "Studies of premixed flame propagation in explosion tubes", Combustion and Flame, 116, 504-518 (1999)

[6] Masri, A.R., Ibrahim, S.S., Nehzat, N. and Green, A.R., "Experimental study of premixed flame propagation over various solid obstructions", Experimental Thermal and Fluid Science, 21, 109-116 (2000)
[7] Ibrahim, S.S. and Masri, A.R., "The effects of obstructions on overpressure resulting from premixed flame deflagration", Journal of Loss Prevention in the Process Industries, 14, 213-221 (2001)

[8] Ibrahim, S.S., Hargrave, G.K., and Williams, T.C., "Experimental investigation of flame/solid interactions in turbulent premixed combustion", Experimental Thermal and Fluid Science, 24, 99-106 (2001)

[9] Hargrave, G.K., Jarvis S.J. and Williams T.C., "A study of transient flow turbulence generation during flame/wall interactions in explosions", Measurement Science and Technology, 13, 1036-1042 (2002)

[10] Park, D.J., Green, A.R., Lee, Y.S. and Chen, Y.C., "Experimental studies on interactions between a freely propagating flame and single obstacles in a rectangular confinement", Combustion and Flame, 150, 27-39 (2007)

[11] Park, D.J., Ahn, J.J. and Lee, Y.S., "Experimental studies on the interaction between a propagating flame and multiple obstacles in a rectangular chamber", KIGAS, 15(1), 54-61, (2008)

[12] Han, J.B., Lee, Y.S. and Park, D.J.,, "Measurements on effects of locations of obstacles in an explosion chamber", KIGAS, 12(8), 67-74, (2008) 